\title{
Differential Distribution of the Synapsins in the Rat Olfactory Bulb
}

\author{
Leslie M. Stone, ${ }^{1}$ Michael D. Browning, ${ }^{2}$ and Thomas E. Finger ${ }^{1}$ \\ 'Department of Cellular and Structural Biology, Rocky Mountain Taste and Smell Center, and 2Department of \\ Pharmacology, Neuroscience Program, University of Colorado School of Medicine, Denver, Colorado 80262
}

The distribution of the different forms of synapsin in the rat olfactory bulb was investigated by biochemical and immunocytochemical methods. Western blots of tissue derived from microdissection of the surface and core regions of the olfactory bulb were performed using antibodies to synapsin I and synapsin II. The relative levels of the synapsins in the core region of the olfactory bulb were similar to the cerebral cortex. In contrast, the surface region of the olfactory bulb had significantly higher levels of synapsin lla and significantly lower levels of synapsin I, relative to the cortex. Immunocytochemical localization of synapsin I and synapsin II revealed that synapsin I immunoreactivity was the most dense in the external plexiform layer and in the glomeruli; immunoreactivity was also present in the granule cell layer and the periglomerular regions. Synapsin II immunoreactivity was the most dense in the glomeruli. The external plexiform layer, internal plexiform layer, and granule cell layer exhibited much lower immunoreactivity. To determine the source of synapsin II immunoreactivity in the glomeruli, the olfactory epithelium was damaged to decrease the primary afferent input to the bulb. Three to four days later, olfactory bulb sections were double labeled with anti-olfactory marker protein (OMP) antibodies and anti-synapsin II antibodies. Following denervation, both OMP and synapsin II immunoreactivities were diminished, and continued to colocalize in regions retaining immunoreactivity. Individual puncta were immunoreactive for both OMP and synapsin II. Occasional puncta contained only synapsin II immunoreactivity.

These results indicate that the distribution of the synapsins in the olfactory bulb differs from most other brain regions. Specifically, synapsin II immunoreactivity is concentrated in the olfactory receptor nerve terminals located in the glomeruli. The unusual concentration of synapsin II in these terminals may be related to the continual remodeling of these synaptic contacts or to other specialized features of olfactory neurotransmission.

[Key words: nerve terminal, olfactory epithelium, olfactory receptor cell, phosphoprotein, smell, synaptic vesicle]

\footnotetext{
Received Nov. 27, 1992; revised June 16,1993; accepted July 8, 1993.

We are grateful to Dr. Frank Margolis, Roche Institute of Molecular Biology, Nutley, NJ, for the anti-olfactory marker protein antibody used in these studies. This work was supported in part by NIH Grant P01DC00244 to T.E.F. and hy Grants AA03527 and AG04418 to M.D.B.

Correspondence should be addressed to Leslie Stone, Department of Cellular and Structural Biology, Campus Box B-111, University of Colorado School of Medicine, 4200 East Ninth Avenue, Denver, CO 80262.

Copyright (C) 1994 Society for Neuroscience $0270-6474 / 94 / 140301-09 \$ 05.00 / 0$
}

The synapsins are a family of homologous synaptic vesicleassociated phosphoproteins thought to be involved in the regulation of neurotransmitter release (Bähler et al., 1990). There are four known synapsins: synapsin Ia, Ib, IIa, and IIb. The amino terminal and central regions of each of these proteins appear to be homologous. Phosphorylation sites for cAMP-dependent protein kinase and $\mathrm{Ca}^{2+} /$ calmodulin-dependent protein kinase $I$ are present in the amino terminal region of each synapsin; binding sites for both actin and synaptic vesicles are located in the central region (Südhof et al., 1989). The four synapsin forms differ in the carboxyl terminal regions. One result of these differences is that synapsins $\mathrm{Ia}$ and $\mathrm{Ib}$ contain phosphorylation sites for $\mathrm{Ca}^{2+} /$ calmodulin-dependent protein kinase II whereas synapsin IIa and IIb do not.

Although each of the four synapsins is widely distributed in the CNS, individual nerve terminals contain different amounts of each type of synapsin (Südhof et al., 1989). In general, synapsin I is more prevalent than synapsin II, at a ratio of $2: 1$ (Finger and Browning, 1990). In addition, the ratios of synapsin Ia to Ib and IIa to IIb are both consistently 1:2 (Walaas et al., 1988). In the olfactory bulb, however, these ratios are different (Finger and Browning, 1990; Dino et al., 1991). The ratio of synapsin IIa to IIb is $3: 2$ instead of the usual $1: 2$, and the ratio of synapsin II to synapsin I is higher in the olfactory bulb than in other brain areas (Browning et al., 1987; Finger and Browning, 1990; M. D. Browning, unpublished observations). Interestingly, in peripheral ganglia (e.g., ciliary and superior cervical ganglia) the levels of synapsin II are high relative to those of synapsin I (Bergman et al., 1992).

We were interested in identifying the neuronal elements in the olfactory bulb that are responsible for the unusual synapsin distribution. The olfactory bulb can be divided into six layers based on cell types and interactions (see Fig. 1). These layers (from the outside in) are the olfactory nerve layer, glomerular layer, external plexiform layer, mitral cell layer, internal plexiform layer, and granule cell layer (Scott and Harrison, 1987). The olfactory nerve layer consists of the axons of the olfactory receptor cells whose somata are located in the olfactory epithelium. These axons extend through the olfactory nerve layer to the glomerular layer, which contains the glomeruli and periglomerular neurons. In the glomerulus, the receptor cell axon terminals synapse on to the dendrites of mitral cells, tufted cells, and periglomerular cells. The mitral cells and some of the tufted cells are output neurons for the olfactory bulb; other tufted cells are local interneurons. Periglomerular cells are involved in local interactions, some of which involve reciprocal dendrodendritic synapses with the mitral/tufted cell dendrites located within the 


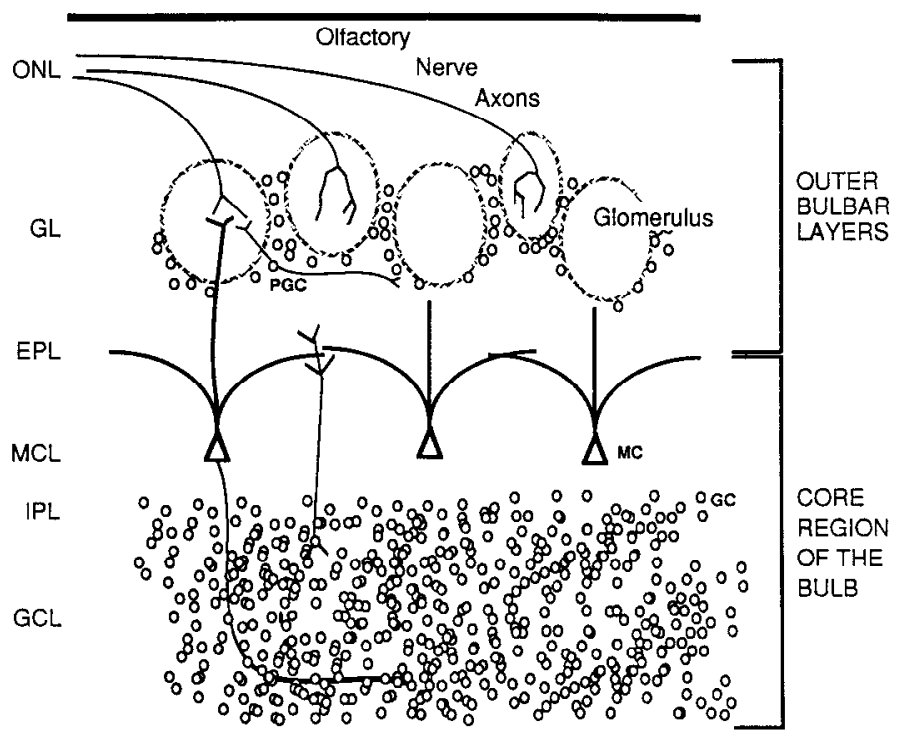

Figure 1. Diagram of olfactory bulb layers. The olfactory nerve layer consists of the axons of the olfactory receptor cells. Glomeruli and periglomerular cells $(P G C)$ make up the glomerular layer. Within the glomeruli, receptor cell axon terminals synapse onto the dendrites of mitral cells, tufted cells, and periglomerular cells. Dendrodendritic synapses between granule cells and mitral/tufted cells are located in the external plexiform layer. Mitral cells and some granule cells are located in the mitral cell layer; mitral cells extend dendrites to the glomeruli. The granule cell layer contains granule cells that extend into the external plexiform layer to synapse with the dendrites of mitral cells. $O N L$, olfactory nerve layer; $G L$, glomerular layer; $E P L$, external plexiform layer; $M C L$, mitral cell layer; $I P L$, internal plexiform layer; $G C L$, granular cell layer; $P G C$, periglomerular cell; $M C$, mitral cell; $G C$, granule cell.

glomeruli. The external plexiform layer contains tufted cells, some of which are output cells, while others send axons within the olfactory bulb. This layer predominantly contains dendrodendritic synapses between granule cells and mitral/tufted cells. The mitral cell layer contains mitral cells as well as some granule cells; the mitral cells in this layer extend dendrites through the external plexiform layer to the glomeruli. The internal plexiform layer is a thin layer that contains collaterals of axons from mitral cells, tufted cells, and cells that project to the olfactory bulb from the forebrain; no cell bodies lie in this layer. The granule cell layer receives synaptic input from several forebrain regions including the olfactory cortex. Interneuronal connections are also present in this layer. Granule cell dendrites do not reach into the glomeruli, but do extend into the external plexiform layer, where they form dendrodendritic synapses with dendrites of the mitral cells.

For this study, the differential distribution of synapsin I and synapsin II in the olfactory bulb was examined by two separate techniques. The first was microdissection of the surface and core regions of the olfactory bulb, followed by Western blots of these tissues using antibodies to synapsin I and synapsin II. The second technique involved immunocytochemistry to localize synapsin I and synapsin II to specific regions in sections of the olfactory bulb. To test whether the unusual distribution of synapsins in the olfactory bulb was attributable to the olfactory nerve input, the olfactory epithelium in rats was chemically damaged (Nadi et al., 1981), and 3-5 d later the effect of this lesion on the olfactory bulb, especially the glomeruli, was determined.

\section{Materials and Methods}

Microdissection. The method employed for microdissection of the outer and inner layers of the bulb was developed through histological analysis of practice tissue dissections. The method ultimately adopted involved rapid removal of the bulbs from an anesthetized animal and freezing them lateral side down onto the stage of a freezing, sliding microtome. Freehand-cut sections approximately $300 \mu \mathrm{m}$ thick were taken in the horizontal plane from the dorsal and ventral surfaces of the bulb. A similar-sized section in the transverse plane was taken from the anterior end of the bulb. In addition, the microtome was used to cut three 100 $\mu \mathrm{m}$ sections in the parasagittal plane from the medial surface of the bulb. These sections as well as the freehand-cut sections described above constituted the "outer bulbar layers" fraction. This tissue includes the glomerular layer and the olfactory nerve layer as well as some of the external plexiform layer from the medial, dorsal, ventral, and anterior faces of the olfactory bulb. Four or five $100-\mu \mathrm{m}$-thick parasagittal sections then were collected as the "central region" of the bulb. This tissue included the granule and mitral cell layers as well as the inner portion of the external plexiform layer (see Fig. 1).

Immunoblot assay of synapsin I and synapsin II levels. Microdissected tissues were sonicated in $200 \mu \mathrm{l}$ of $1 \%$ SDS in distilled water. Levels of synapsin I, synapsin IIa, and synapsin IIb were assayed using quantitative immunolabeling as described previously (Browning et al., 1987). Briefly, tissue samples were subjected to SDS-PAGE on $7.5 \%$ gels. The samples were electrophoretically transferred to nitrocellulose sheets (BA $83,0.2 \mathrm{~mm}$, Schleicher \& Schuell) for $8 \mathrm{hr}$ at $20 \mathrm{~V}$. After transfer, the sheets were incubated in buffer A (final concentrations, $150 \mathrm{mM} \mathrm{NaCl}$, $25 \mathrm{~mm}$ Tris/ $\mathrm{HCl}, \mathrm{pH} 7.4,10 \mathrm{~mm}$ EDTA, $0.05 \%$ sodium azide, and $0.05 \%$ Tween-20) to block nonspecific absorption. The sheets then were exposed to affinity-purified synapsin antibody in buffer A for $2 \mathrm{hr}$. After $3 \times 20$ min washing in incubation buffer, the sheets were incubated with ${ }^{125}$ I-protein A. Immunoreactive bands were localized by autoradiography and after excision of the bands ${ }^{125}$ I-protein $A$ was quantified in a gamma counter. Concentrations of synapsin I and synapsin II were determined by comparison with purified rat protein standards that had been run on the same gel as described previously. This assay is sensitive to as few as 10 fmol of synapsin I or synapsin II.

Perfusion and sectioning. Sprague-Dawley rats were anesthetized with pentobarbital $(64.8 \mathrm{mg}$, i.p.) or with chloral hydrate $(350 \mathrm{mg} / \mathrm{kg}$, i.p.) and fixed by cardiac perfusion with $400 \mathrm{ml}$ of $4 \%$ paraformaldehyde. Following perfusion, the brain was removed and placed in the same fixative with $20 \%$ sucrose for cryoprotection overnight. The next day, the brain was transferred to $20 \%$ sucrose in $0.1 \mathrm{~m}$ phosphate buffer and soaked for an additional hour. Sections were then cut on a sliding, freezing stage microtome $(40 \mu \mathrm{m})$ or on a cryostat $(5 \mu \mathrm{m})$. Microtome sections were collected in $0.1 \mathrm{M}$ phosphate buffered saline (PBS), pH 7.2 , and cryostat sections were collected on gelatin-coated slides.

Immunocytochemistry. The primary antibodies used were rabbit antisynapsin I (\#7403; dilution, 1:100), mouse anti-synapsin II (\#19.21; dilution, 1:100 or 1:500), and goat anti-olfactory marker protein (OMP) (lot 255, Frank Margolis, Roche Institute; 1:5000 or 1:10,000 dilution). Anti-synapsin antibodies were prepared as described previously (Browning et al., 1987). Normal rabbit serum, normal mouse ascites, and normal goat serum replaced the appropriate primaries in control sections; all were used at a dilution of 1:100. Some sections were double labeled with anti-synapsin I and anti-synapsin II, or with anti-OMP and anti-synapsin II antibodies. All dilutions were made using $0.1 \mathrm{M}$ phosphate-buffered saline (pH 7.2) with $0.3 \%$ Triton X-100 (TPBS). Sections were incubated in primary antibodies at $4^{\circ} \mathrm{C}$ for $2.5-3 \mathrm{~d}$.

After being washed in buffer, the sections were incubated in secondary antibodies for $1.5-2 \mathrm{hr}$ at room temperature. All secondary antibodies were preabsorbed at the time of manufacture to eliminate cross-reactivity with inappropriate IgG species. In addition, controls were carried out to test for inappropriate cross-reactivity with the primary antisera employed in these experiments. No cross-reactivity of the secondary antibodies with primary antibodies of inappropriate species was detected.

Secondary antibodies used for single-labeled sections were biotinylated donkey anti-rabbit [Jackson Immunoresearch Laboratories, Inc. (JIL), lot $12751 ; 1: 5000$ dilution] and biotinylated rat anti-mouse (JIL, lot 13558; 1:5000 dilution). The sections were then reacted with an avidin-biotin complex (ABC) peroxidase system (Vectastain Elite kit) according to the directions supplied in the kit. Sections were mounted on gelatin-coated slides and coverslipped using Permount (Fisher Scientific). 


\section{Synapsin I Synapsin Ila $\simeq$ Synapsin Ilb-}

synapsin II antibodies, 1:100 rhodamine donkey anti-goat (JIL, lot 11660) and 1:100 FITC rat anti-mouse secondaries were used. Forty micrometer sections were mounted on gelatin-coated slides and both $40 \mu \mathrm{m}$ and $5 \mu \mathrm{m}$ sections were coverslipped using Fluoromount (Fisher Biotech).

Photography. Sections labeled with the ABC method were photographed using a Zeiss ultraphot microscope; fluorescently labeled sections were photographed using a Zeiss standard microscope equipped for epifluorescence. For double-labeled sections, rhodamine and fluorescein labeling were viewed separately using Zeiss filter cube 487710 with an added long-wave cutoff (excitation = BP 450-490 nm; barrier $=$ BP $520-560 \mathrm{~nm}$ ) for fluorescein and filter cube 487714 (excitation = BP $515-560 \mathrm{~nm}$; barrier $=$ LP $590 \mathrm{~nm}$ ) for rhodamine. TMAX-100 film was used for black and white prints. In addition, some sections were viewed on a Bio-Rad 600 laser scanning confocal microscope equipped with a helium-xenon laser and $\mathrm{K} 1$ and $\mathrm{K} 2$ filter blocks for simultaneous analysis of FITC and rhodamine fluorescence. These images were processed on a Macintosh II X computer using Adobe PHOTOSHOP (2.0.1) software, and printed on a Kodak XL7700 printer.

Surgical techniques. Sprague-Dawley rats ranging in weight from 90 to $453 \mathrm{gm}$ were anesthetized with ketamine $(0.85 \mathrm{ml} / \mathrm{kg}$, i.p.) and $\mathrm{xy}-$ lazine $(0.35 \mathrm{ml} / \mathrm{kg}$, i.p.). Supplemental doses were given when required for proper anesthesia. The animal was placed in a stereotaxic frame and a 1-2 cm sagittal incision was made above the nasal cavity. Some of the bone above one side of the nasal epithelium was removed and cotton or Gelfoam soaked in $10 \%$ zinc sulfate was placed into this area and pushed toward the cribriform plate where the olfactory epithelium is concentrated. Dry Gelfoam was placed over the hole in the bone, and the incision sutured. This procedure resulted in a rat with a unilateral lesion; the normal side was used as a control. All rats were given Tylenol Liquid following the surgery and permitted to survive 3-5 d before perfusion fixation.

Figure 2. Autoradiogram demonstrating specificity of antisera. ferred to nitrocellulose. Strips of the nitrocellulose were then incubated in antisera followed by ${ }^{125}$ I-protein A. Antibody 19.21 is a mouse monoclonal antibody raised against synapsin IIb, as was the rabbit polyclonal antibody $35 / 36$. Antibody 7403 was raised against purified synapsin I.

For double-labeled sections, a mixture of secondary antisera was employed. Sections labeled with anti-synapsin I and anti-synapsin II antibodies were placed in TPBS containing 1:100 rhodamine donkey antirabbit (JIL, lot 10771) and 1:100 fluorescein isothiocyanate (FITC) rat anti-mouse (JIL, lot 10665). For sections double labeled with OMP and

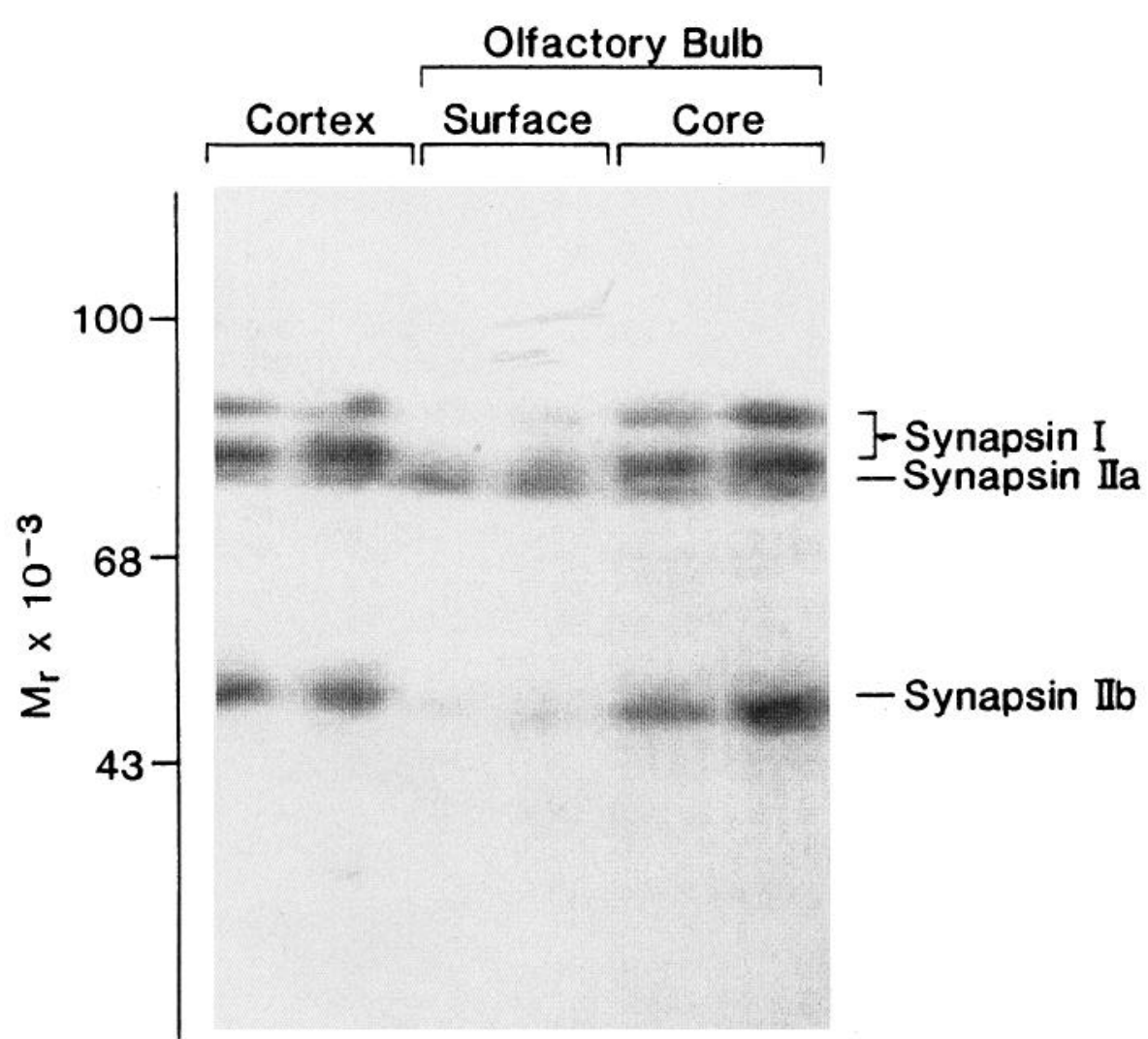

\section{Results}

\section{Specificity of antisera}

The specificity of the antisera used in this study is depicted in the autoradiogram in Figure 2. Antisera 19.21 and 35/36 were raised against purified synapsin IIb while antiserum 7403 was raised against purified synapsin I. As shown in Figure 2, anti- 




Figure 4. Quantitative analysis of Western blot data. Histograms illustrating the quantitative analysis of the immunoblot analyses shown in Figure 3. The molar ratio of synapsin I to synapsin II is $1.83 \pm 0.03$ in cerebral cortex and $1.70 \pm 0.11$ in the core region of the olfactory bulb. In contrast, this ratio is significantly smaller in the surface region of the olfactory bulb $\left(1.16 \pm 0.11 ;{ }^{* *}, p<0.01\right)$. Moreover, the ratio of synapsin IIa to synapsin IIb is only $0.46 \pm 0.23$ in cerebral cortex, while this ratio is substantially higher $(1.78 \pm 0.32 ; *, p<0.05)$ in the surface region of the olfactory bulb. This ratio is also slightly higher $\left(0.73 \pm 0.07 ;^{*}, p<0.05\right)$ in the core region of the olfactory bulb when compared to cerebral cortex. Values are expressed as \pm SEM.

serum 19.21, which is a mouse monoclonal antibody, recognizes only synapsin IIa and synapsin IIb in Western blots of rat cortex. In contrast, antiserum 35/36, which is a pool of antisera from two rabbits and which had been affinity purified on a synapsin
Table 1. Average pixel brightness for synapsin I and synapsin II immunoreactivity

\begin{tabular}{lrr} 
Region & Synapsin I & Synapsin II \\
\hline Olfactory nerve layer & $0 \pm 12$ & $0 \pm 9$ \\
Glomeruli & $100 \pm 12$ & $353 \pm 26$ \\
Periglomerular regions & $55 \pm 18$ & $77 \pm 13$ \\
External plexiform layer & $100 \pm 9$ & $100 \pm 13$ \\
Granular layer & $9 \pm 6$ & $49 \pm 13$
\end{tabular}

Rat olfactory bulb sections were reacted with anti-synapsin I or anti-synapsin II antibodies, followed by fluorescently tagged secondary antibodies. Fluorescent images were digitized and the average pixel brightness for each layer was calculated using IMAGE software (version 1.44b39). Immunoreactivity for each layer is expressed relative to that of the external plexiform layer, which was set at a value of 100 , and the olfactory nerve layer, which was set at a value of 0 . Meaningful comparisons can be made only between different layers labeled with the same antibody (i.e., within a column); comparisons between columns are not valid. Values are expressed as $\pm \mathrm{SD}$

I affinity column, recognizes synapsins I, IIa, and IIb. Lastly, antiserum 7403 recognizes only synapsin I. Antiserum 35/36 was not used in the anatomical experiments reported in this article since it is not specific for synapsin I or II (see Fig. 2).

\section{Ratios of the synapsins}

We examined the relative levels of the synapsins in cerebral cortex and in the core and surface regions of the olfactory bulb using a quantitative Western blot analysis. As can be seen in Figure 3, the core region of the olfactory bulb has relative levels of the synapsins that are very similar to those in the cerebral
Figure 5. Synapsin I and synapsin II immunoreactivity in the rat olfactory bulb. Forty micrometer sections of rat olfactory bulb were double labeled with rabbit anti-synapsin I antibodies and mouse anti-synapsin II antibodies. These primary antibodies were followed by rhodamine donkey anti-rabbit and fluorescein isothiocyanate rat anti-mouse secondary antibodies. Note that synapsin I immunoreactivity is the most dense in the external plexiform layer and the glomeruli; synapsin II immunoreactivity is concentrated in the glomeruli. GLOM, glomerular layer; $E P L$, external plexiform layer; $G L$, granule cell layer.
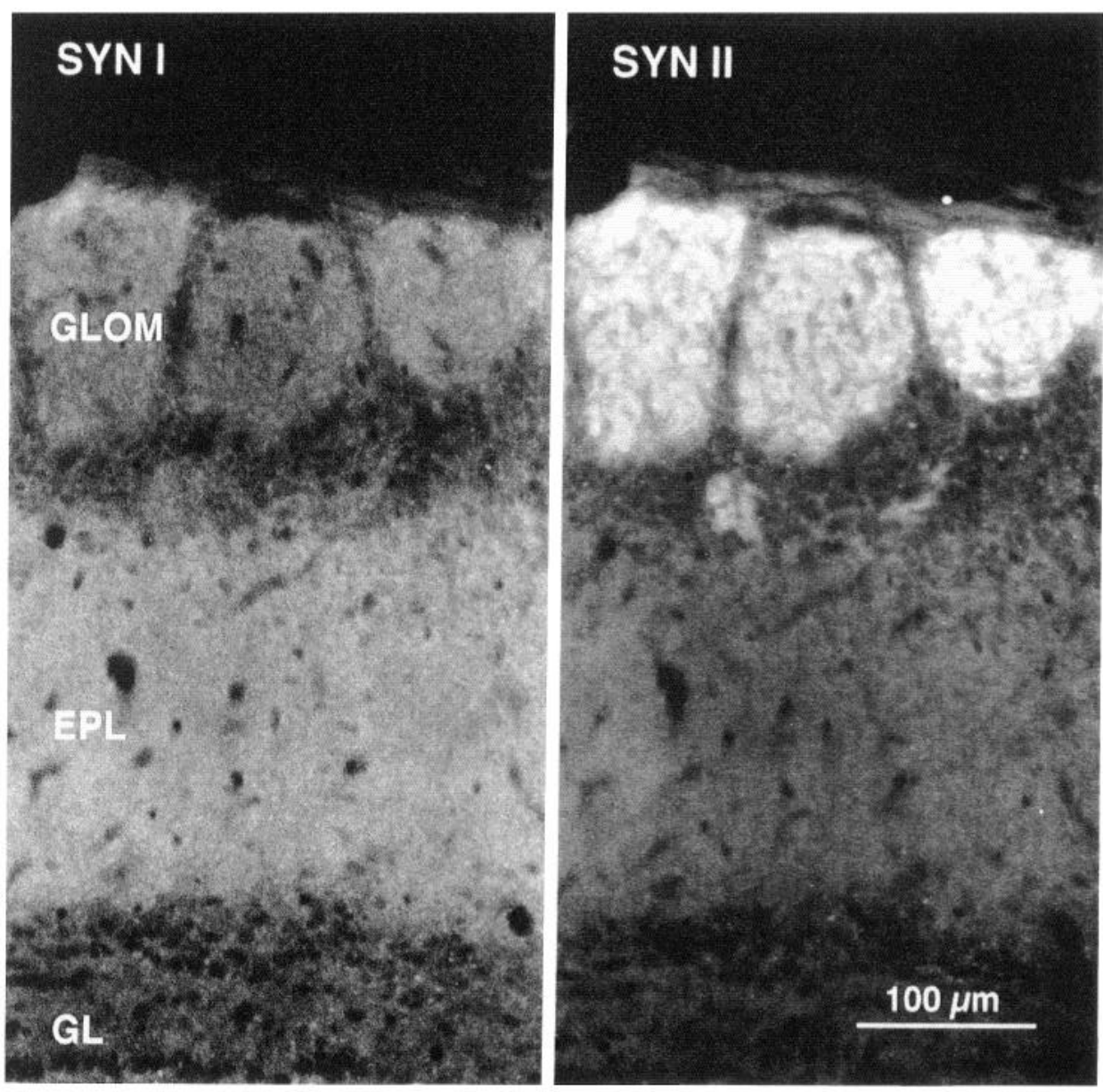

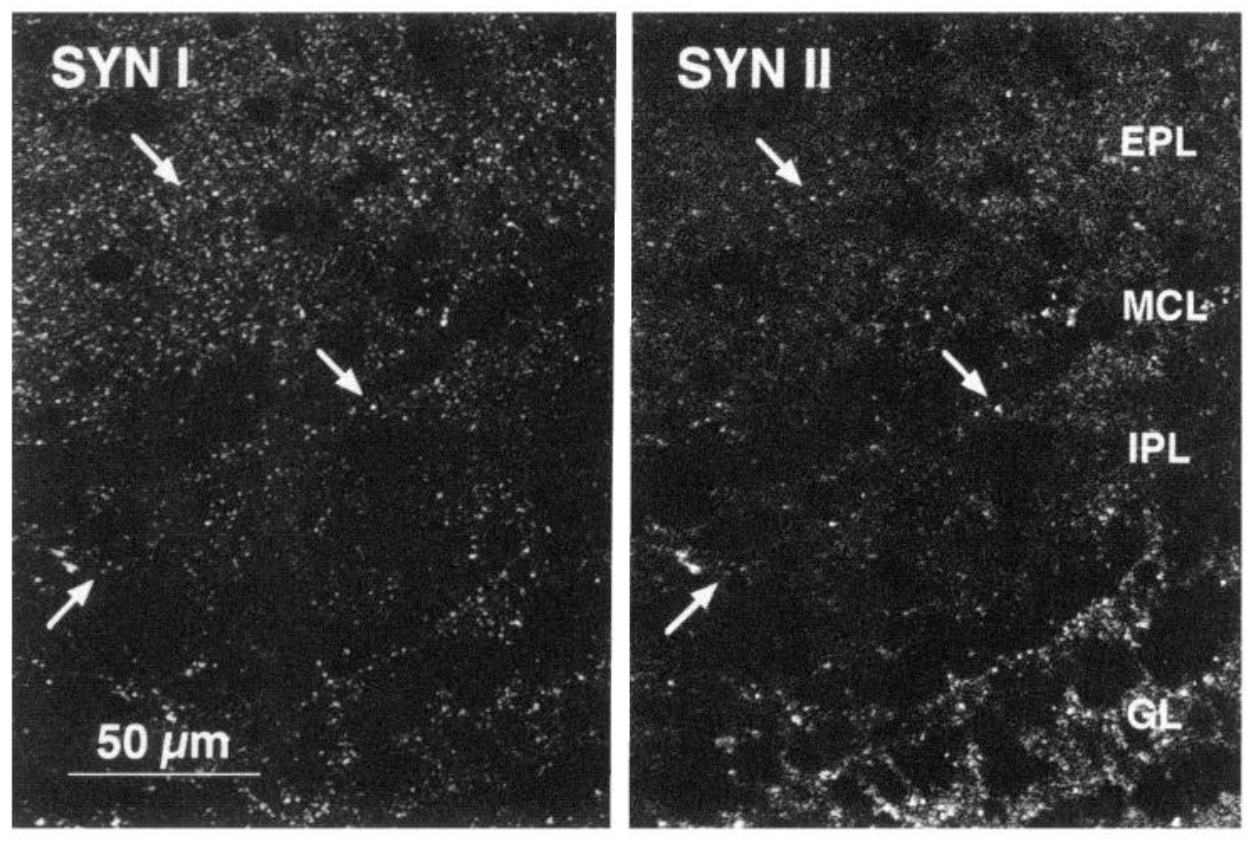

Figure 6. Confocal image of synapsin I and synapsin II immunoreactivity in the deeper layers of the olfactory bulb. Forty micrometer sections were double labeled with anti-synapsin I and antisynapsin II antibodies followed by fluorescently labeled secondary antibodies. Two confocal scans $2 \mu \mathrm{m}$ apart were collected and added together to produce each image. Arrows indicate puncta containing both synapsin I and synapsin II immunoreactivity.

cortex. Synapsin I is the predominant form of the synapsins in the cortex and the core region while the relative amount of synapsin IIa is quite low in these regions. In contrast, in the surface region of the olfactory bulb the relative amount of synapsin I is quite low and synapsin IIa is the predominant form of the synapsins. Quantitative analysis of these Western blot data are shown in Figure 4. As these data clearly show, the surface region of the olfactory bulb has significantly higher relative levels of synapsin IIa and significantly lower relative levels of synapsin I when compared to cortex. In contrast, the ratio of synapsin I to synapsin II in the core region of the olfactory bulb is virtually identical to that seen in the cerebral cortex. However, the ratio of synapsin IIa to synapsin IIb is slightly higher in the core region than in the cerebral cortex. This may be due to slight contamination from the surface region in microdissected core samples.

\section{Synapsin I and synapsin II immunoreactivity}

Antibodies to synapsin I and synapsin II were applied to $5 \mu \mathrm{m}$ and $40 \mu \mathrm{m}$ sections of rat olfactory bulb. These primary antibodies were followed by fluorescent or biotinylated secondary antibodies. Both fluorescent labeling and avidin-biotin peroxidase labeling of anti-synapsin I and II antibodies resulted in immunoreactivity that clearly showed the laminated structure of the olfactory bulb. The olfactory nerve layer, glomerular layer, and external plexiform layer were distinct from each other and from the deeper layers of the bulb. However, the mitral cell layer, internal plexiform layer, and granule cell layer could be differentiated only under high magnification. Control sections that were not exposed to primary antibodies did not have clearly visible layers; the reaction product in controls was lightly scattered throughout the section, except at the very outer edge where the reaction was more dense.

To quantitate differences in immunoreactivity between the olfactory bulb layers for each antibody, fluorescent images were digitized and the average brightness for each layer was calculated using IMAGE $1.44 \mathrm{~b} 39$ (W. Rasband, NIH) software. These values are presented in Table 1.

\section{Synapsin I immunoreactivity}

Immunoreactivity for synapsin I was the most dense in the external plexiform layer and the glomeruli, as shown in Figure 5 and Table 1. Some immunoreactivity was also present in the periglomerular regions and the deeper layers of the bulb; the olfactory nerve layer contained little immunoreactivity. In general, differences in the density of immunoreactivity were due to differences in both punctate and diffuse reaction product, as shown in Figure 6. Puncta in each layer were consistently 1-2 $\mu \mathrm{m}$ in diameter.

Punctate immunoreactivity in the olfactory nerve layer was rare. A diffuse precipitate present in the outer third of this layer was seen in both control sections and sections exposed to primary antibody and is attributed to an edge artifact. Within the glomerular layer, immunoreactivity was present in both glomeruli and periglomerular regions; however, it was most dense in the glomeruli (see Fig. 5, Table 1). The immunoreactivity within and between glomeruli in a section was heterogeneous. In general, immunoreactivity was most dense in the outer onefourth to one-half of the glomerulus, that is, closest to the olfactory nerve layer. However, glomeruli with more dense immunoreactivity did not appear to be located in any particular region of the bulb. Although the immunoreactivity within glomeruli was generally diffuse, some immunoreactive puncta also were observed. Both the diffuse and punctate immunoreactivities were present in patterns that were surrounded and outlined by nonimmunoreactive regions, as shown in Figure 5 (puncta cannot be detected in this photograph). Periglomerular regions also contained both punctate and diffuse immunoreactivity that surrounded and outlined periglomerular cell bodies. Synapsin I immunoreactivity was the highest in the external plexiform layer and both punctate and diffuse immunoreactivity contributed to this effect (Fig. 6). The immunoreactivity was evenly distributed, surrounding and outlining some cell bodies and covering 

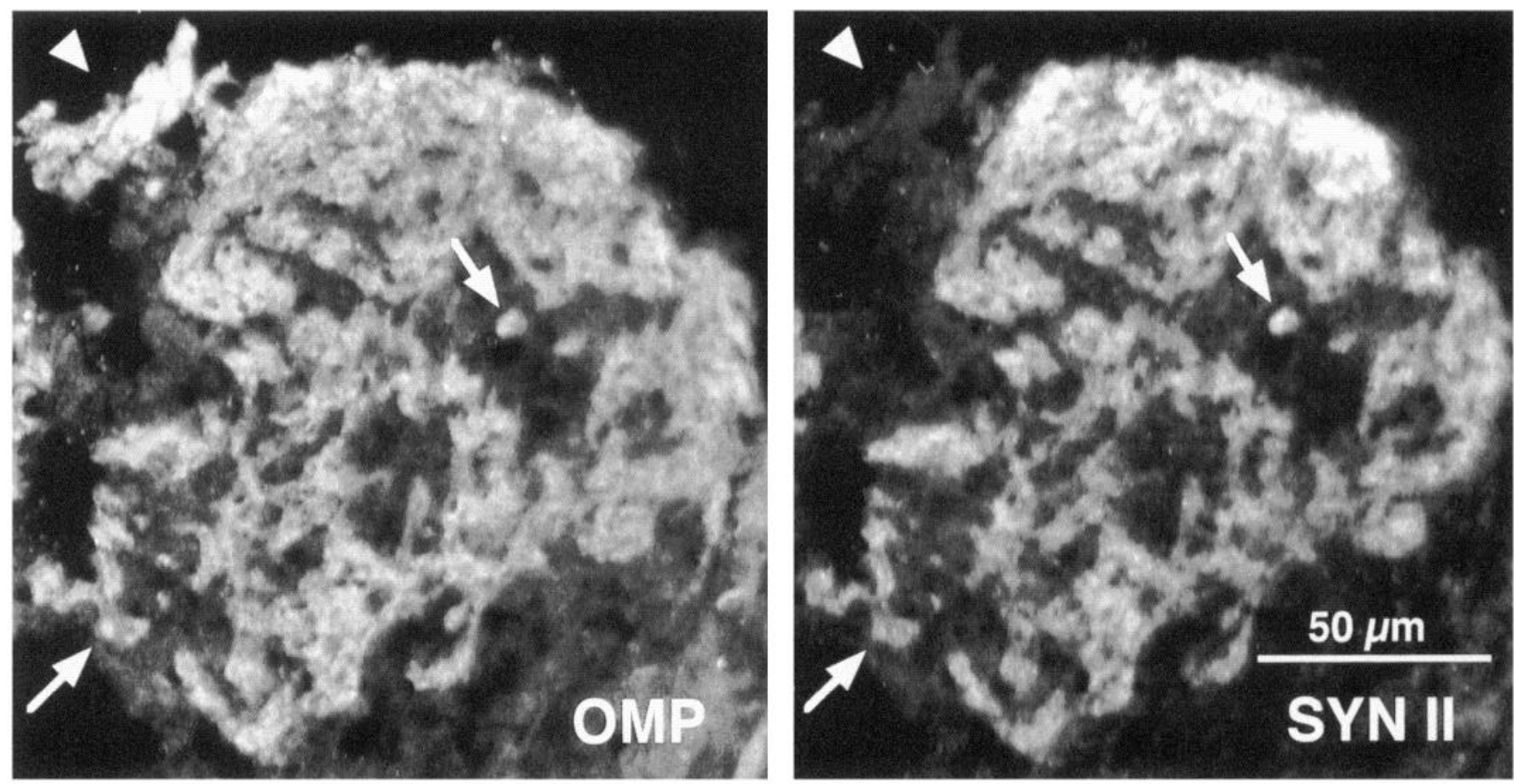

Figure 7. OMP and synapsin II colocalization in rat olfactory bulb sections. Five micrometer rat olfactory bulb sections were double labeled with goat anti-OMP and mouse anti-synapsin II antibodies, followed by rhodamine donkey anti-rabbit and fluorescein isothiocyanate rat anti-mouse secondary antibodies. Arrows indicate OMP and synapsin II colocalization within the glomeruli. Arrowhead indicates the olfactory nerve, which shows abundant OMP immunoreactivity but lacks synapsin II immunoreactivity. OMP, olfactory marker protein immunoreactivity; Syn II, synapsin II immunoreactivity.

others. Regions lacking neuronal cell bodies also contained dense immunoreactivity. Moderate synapsin I immunoreactivity was also present in the mitral cell layer, internal plexiform layer, and granule cell layer, as seen in Figure 6.

\section{Synapsin II immunoreactivity}

Synapsin II immunoreactivity was the most dense in the glomeruli (see Fig. 5, Table 1). Some immunoreactivity was present in the external plexiform layer, with less in the deeper layers and the olfactory nerve layer. Similar to synapsin I immunoreactivity, both diffuse and punctate immunoreactivity were present in all layers and puncta were $1-2 \mu \mathrm{m}$ in diameter (see Fig. 6).

Reaction product in the olfactory nerve layer was concentrated in the outer $25-55 \mu \mathrm{m}$ of this layer. Similar reactivity also was present in control sections and was attributed to an edge artifact. The glomeruli contained the most dense specific immunoreactivity, as shown in Figure 5. It was heterogeneous within and between glomeruli in a single section, and both diffuse and punctate immunoreactivity were evident (not shown). In glomeruli with patchy immunoreactivity, the most dense regions generally were located in the outer one-third to one-half of the glomerulus, closest to the olfactory nerve layer. In sections double labeled with anti-synapsin I and anti-synapsin II antibodies, the patterns of immunoreactivity in the glomeruli were generally similar. Regions with high synapsin II immunoreactivity also exhibited high synapsin I labeling. However, some regions contained moderate synapsin I immunoreactivity in the absence of synapsin II labeling, indicating that colocalization of these two proteins was not complete (data not shown). The periglomerular regions of the glomerular layer also contained some punctate synapsin II reaction product (data not shown).
Although the external plexiform layer, internal plexiform layer, and granule cell layer contained much less synapsin II immunoreactivity, relative to the glomeruli (Fig. 5, Table 1), puncta were more prevalent in the external plexiform layer and deeper layers than in the glomeruli (see Fig. 6). In each of these layers, the punctate immunoreactivity surrounded and covered cell bodies. Puncta were the most dense between the linear arrays of cell bodies within the granule cell layer. The lower density in this layer indicated by Table 1 may be due to a greater density of cells in the granule layer, thus leaving less area for immunoreactive puncta (see Fig. 6). Many puncta in the external plexiform layer, internal plexiform layer, and granule cell layer were immunoreactive for both synapsin I and synapsin II, as shown in Figure 6. The deep white matter contained occasional puncta (data not shown). Some of these puncta in the white matter were present as linear arrays $30-100 \mu \mathrm{m}$ long; four to seven such linear arrays were present in each transverse section (white matter length approximately $2.2 \mathrm{~mm}$ ).

Results from microdissection studies and immunocytochemical studies both indicate that a substantial difference exists in the distribution of synapsin I and synapsin II in the olfactory bulb. One of the most prominent differences is the dense synapsin II immunoreactivity within the glomeruli.

\section{Denervation experiments}

To determine whether synapsin II is located in the olfactory receptor nerve terminals or in interneuron nerve terminals within the glomeruli, rat olfactory receptor cells and their axons were damaged by application of zinc sulfate to the nasal epithelium. After 3-5 d, the rat was perfused and olfactory bulb sections were double labeled with anti-OMP antibody and anti-synapsin II antibody. OMP was used as a marker to determine the degree 

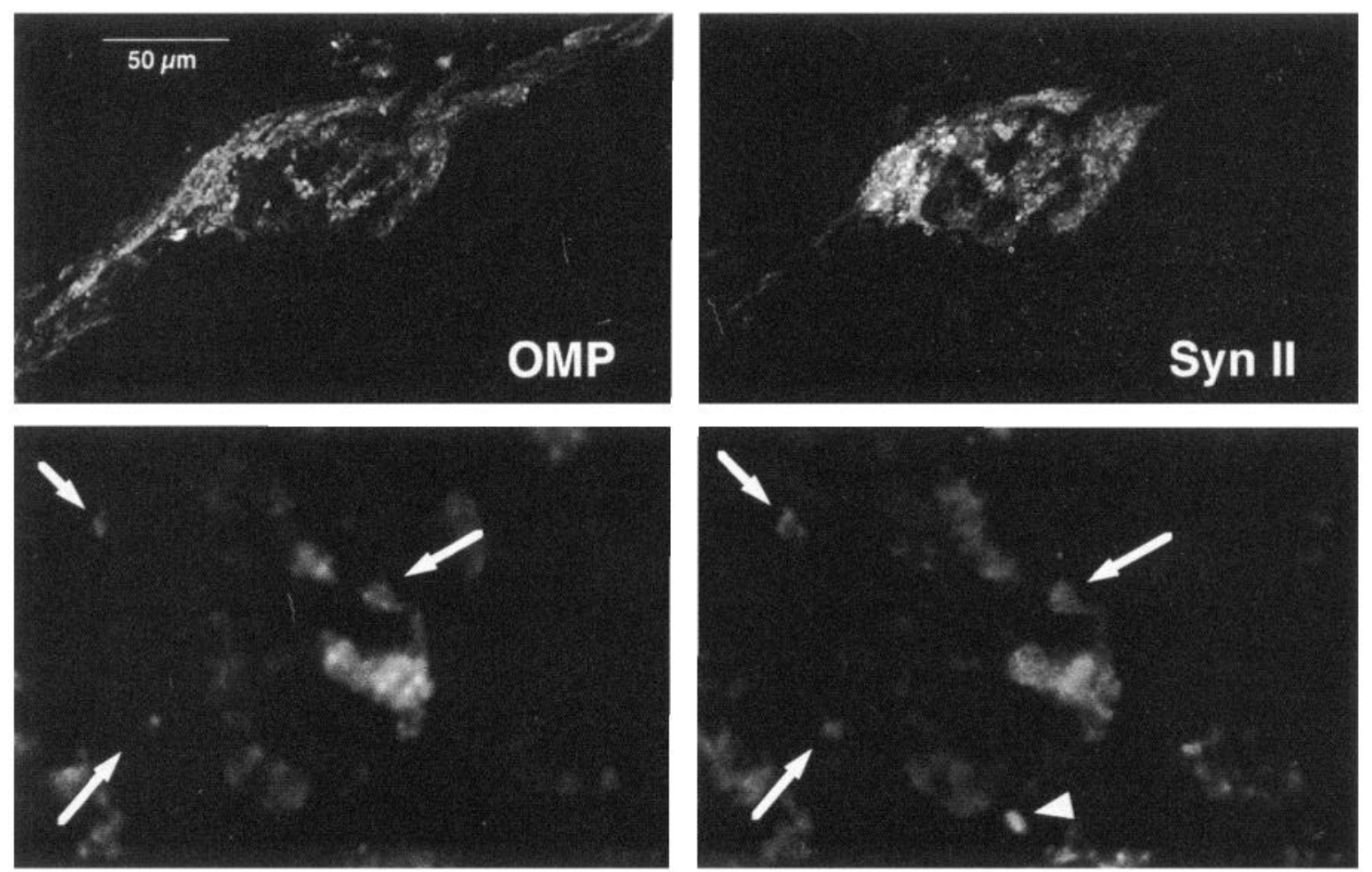

Figure 8. OMP and synapsin II in denervated rat olfactory bulb sections. Rat olfactory receptor cells and their axons were damaged by application of zinc sulfate to the nasal epithelium. Three to four days later, the rat was perfused and olfactory bulb sections were double labeled with goat antiOMP and mouse anti-synapsin II antibodies, followed by rhodamine donkey anti-rabbit and fluorescein isothiocyanate rat anti-mouse secondary antibodies. Magnification of the bottom two pictures is approximately 10 times that of the top pictures. Arrows indicate colocalization of OMP and synapsin II immunoreactivity in a partially denervated glomerulus. Arrowhead indicates a glomerular region containing synapsin II immunoreactivity in the absence of OMP immunoreactivity.

of denervation of the olfactory epithelium. OMP immunoreactivity in the bulb derives from primary olfactory receptor neurons (Margolis, 1972; Monti-Graziadei et al., 1977), so a decrease of OMP immunoreactivity was used to indicate that the receptor cells and their axons were damaged.

The distributions of OMP and synapsin II immunoreactivity were similar in a normal olfactory bulb and in the unlesioned side of the experimental animals (see Fig. 7). OMP fluorescence was the most dense in the olfactory nerve layer and within the glomeruli; immunoreactivity in periglomerular regions and deeper layers of the bulb was minimal. This distribution corresponds to the locations of olfactory receptor cell axons and their terminals, which do not extend beyond the glomeruli. OMP immunoreactivity was mostly diffuse, although some immunoreactive puncta were visible within glomeruli (Fig. 7). Synapsin II fluorescence was the most dense in the glomeruli, as previously indicated. Synapsin II immunoreactivity colocalized with OMP immunoreactivity within glomeruli of double-labeled sections, as shown in Figure 7. However, synapsin II immunoreactivity was concentrated in the nerve terminals of the olfactory neurons and was absent from the fibers that make up the olfactory nerve layer (arrowheads, Fig. 7). In contrast, OMP immunoreactivity is very dense in the olfactory nerve layer. Synapsin II immunoreactivity was primarily diffuse, but puncta also were present in the glomeruli. Both OMP and synapsin II immunoreactivity clearly defined the boundaries of individual glomeruli; within these structures, neither type of immunoreactivity was uniformly distributed; regions of dense immunoreactivity were surrounded and outlined by areas with less dense reaction product (Fig. 7). However, these patterns of variable density were the same for OMP and synapsin II fluorescence. Individual puncta and regions of high density with distinct borders clearly showed the colocalization of both types of fluorescence (see arrows, Fig. 7).

Following denervation, the distribution of immunoreactivity for both synapsin II and OMP was affected. Denervation in these experiments was partial. Only some of the olfactory epithelium was damaged and accordingly the degree of denervation varied between glomeruli. OMP immunoreactivity remained high in the surviving regions of the olfactory nerve layer and was variable within and between glomeruli in a section. Some glomeruli had dense immunoreactivity and appeared to be unaffected by the denervation. Other glomeruli exhibited patchy OMP immunoreactivity; regions with dense immunoreactivity were adjacent to areas with little or no immunoreactivity. The remaining glomeruli had little visible immunoreactivity. All three of these types of glomeruli could be seen within a small area of one section.

Glomeruli that showed a decrease in OMP fluorescence, indicating decreased nerve input, showed a corresponding decrease in synapsin II immunoreactivity. Glomeruli retaining dense OMP immunoreactivity also retained dense synapsin II immunoreactivity. In partially denervated glomeruli, the patterns of OMP and synapsin II immunoreactivity continued to colocalize; regions retaining dense OMP immunoreactivity also retained dense synapsin II immunoreactivity, as shown in Figure 8 . This correspondence was also evident under high magnification (Fig. 8), where individual puncta containing both types 
of fluorescence were evident (arrows). However, some puncta could be identified that contained only synapsin II and not OMP immunoreactivity (arrowhead).

\section{Discussion}

Each member of the synapsin family is closely related to the other members in terms of structure and distribution in the CNS and PNS; some differences may reflect differences in functional roles. Walaas et al. (1988) showed that both synapsin I and synapsin II are widely distributed in the CNS. These proteins were found in all regions examined, including the olfactory bulb, cerebral cortex, hippocampus, basal ganglia, thalamus, hypothalamus, cerebellum, pons-medulla, and spinal cord. Synapsin immunoreactivity also was found in the posterior pituitary. The relative amounts of synapsins Ia, Ib, IIa, and IIb are also usually consistent; in most brain regions synapsin Ia and Ib exhibit a constant ratio of 1:2 (Walaas et al., 1988) as do synapsin Ila and IIb (Browning et al., 1987). In general, synapsin Ib is the most prevalent of the four proteins. For example, in the deep cerebellar nuclei and the nucleus of the trapezoid body of the brainstem, synapsin $\mathrm{Ib}$ appears to be present in all nerve terminals, whereas synapsin IIa is not detectable in some cerebellar synapses; similarly, synapsin IIb is present in only a few synapses in the trapezoid body (Südhof et al., 1989).

The present study clearly demonstrates that synapsin immunoreactivity is differentially expressed in the rat olfactory bulb. Synapsin I immunoreactivity is distributed throughout all synaptic layers; the glomeruli and the external plexiform layer contain the most dense immunoreactivity. In contrast, synapsin II immunoreactivity is concentrated in the glomeruli. Some immunoreactivity also is present in the external plexiform layer, internal plexiform layer, and granule cell layer, but relative to the glomeruli much less immunoreactivity exists deeper in these layers.

The differential distribution of the synapsins in the olfactory bulb is very similar to that seen in the inner plexiform layer of the vertebrate retina. The more uniform distribution of synapsin $I$ in both structures suggests that this protein is present in most synapses, including some unusual types of synapses. For example, synapsin I is prevalent in the external plexiform layer of the olfactory bulb, a layer containing a preponderance of reciprocal dendrodendritic synapses. Because synapsin I immunoreactivity is so dense in this layer, and these synapses are prevalent, synapsin I is probably located in these dendrodendritic synapses. This type of synapse is also present in the glomeruli, between periglomerular dendrites and the apical dendrites of mitral/tufted cells; again, synapsin I occurs in this region. In the retina, synapsin I immunoreactivity is spread throughout the inner plexiform layer and is probably associated with the synaptic terminals of amacrine cells (Mandell et al., 1990). These cells form reciprocal synapses with one another and with bipolar cells, although these synapses are between axonal and dendritic processes rather than being dendrodendritic. These observations suggest that synapsin I is present in most types of synapses, although exceptions exist. For example, ribbon synapses of the vertebrate retina and taste cell-to-afferent nerve fiber synapses both lack these synapsins (Finger et al., 1990; Mandell et al., 1990).

We also have shown that in the glomeruli, and specifically in the olfactory receptor nerve terminals, synapsin II is more prevalent than synapsin I. This reversal in the relative concentrations of the two synapsins compared to other regions of the CNS is also similar to that seen in the retina. Mandell et al. (1992) showed that in the inner plexiform layer, two sublayers (S2 and S4) contain puncta that are immunoreactive to synapsin II but not to synapsin I; furthermore, they suggest that this immunoreactivity may be localized to the synapses of cholinergic amacrine cells. Pussible specialized functions of these synapses include processing presynaptic information without communicating with the soma and the ability to co-release or even differentially release two types of neurotransmitter in response to this input. These authors suggest that synapsin II may be involved in these specialized functions. Perhaps the olfactory receptor nerve terminals also have specialized functions requiring synapsin II. One unusual feature of the synapses between the olfactory axon terminals and the apical dendrites of mitral/ tufted cells or the dendrites of periglomerular cells is that these synapses generally are not permanent. Under typical environmental conditions, significant turnover of olfactory receptors occurs (Moulton et al., 1970; Graziadei and Metcalf, 1971; Mackay-Sim and Kittel, 1991), although some cells may remain in the epithelium for prolonged periods (Mackay-Sim and Kittel, 1991). When olfactory receptors die, their axons and terminals degenerate. New synaptic contacts must then be established between newly formed receptor cells and the bulbar neurons (Moulton, 1974; Graziadei and Monti Graziadei, 1978). Thus, olfactory receptor synapses may not reach the full level of maturity compared to more stable systems. Whether this feature is related to the unusual concentration of synapsin II in these terminals is not clear.

In the glomeruli, synapsin II immunoreactivity is not restricted to the olfactory receptor terminals. As shown in Figure 8 , occasional puncta within glomeruli contain synapsin II immunoreactivity in the absence of OMP immunoreactivity. Therefore, synapsin II also may be located in periglomerular nerve terminals, or mitral/tufted cell dendrites that form dendrodendritic synapses with the periglomerular cells.

In conclusion, our studies have shown that synapsin I and synapsin II are differentially distributed in the rat olfactory bulb. Synapsin I is distributed fairly uniformly throughout the synaptic layers. In contrast, synapsin II is concentrated in the glomeruli, and specifically in the olfactory receptor nerve terminals. This contrasts with most synapses in the CNS, which contain relatively more synapsin I. The concentrated synapsin II in the olfactory receptor nerve terminals may be related to the continual remodeling of these synaptic contacts or other specialized features of olfactory neurotransmission.

\section{References}

Bähler M, Benfenati F, Valtorta F, Greengard P (1990) The synapsins and the regulation of synaptic function. Bioessays 12:259-263.

Bergman H, Browning MD, Granholm A-C (1992) Development of synapsin I and synapsin II in intraocular hippocampal transplants. Hippocampus 2:339-348.

Browning MD, Huang C, Greengard P (1987) Similarities between protein IIIa and protein IIIb, two prominent synaptic vesicle-associated phosphoproteins. J Neurosci 7:847-853.

Dino MR, Mugnaini E, Czernick A, Greengard P (1991) Differential distribution of synapsin isoforms in the main olfactory bulb of the rat. Soc Neurosci Abstr 17:637.

Finger TE, Browning MD (1990) High levels of synapsin Il in olfactory nerve terminals in the olfactory bulb. Soc Neurosci Abstr 16:499.

Graziadei PPC, Metcalf JF (1971) Autoradiographic and ultrastructural observations of the frog's olfactory epithelium. Z Zellforsch 116 : 305-318.

Graziadei PPC, Monti Graziadei GA (1978) The olfactory system: a model for the study of neurogenesis and axon regeneration in mam- 
mals. In: Neuronal plasticity (Cotman CW, ed), pp 131-153. New York: Raven.

Mackay-Sim A, Kittel P (1991) Cell dynamics in the adult mouse olfactory epithelium: a quantitative autoradiographic study. J Neurosci 11:979-984.

Mandell JW, Townes-Anderson E, Czernik AJ, Cameron R, Greengard $P$, De Camilli P (1990) Synapsins in the vertebrate retina: absence from ribbon synapses and heterogeneous distribution among conventional synapses. Neuron 5:19-33.

Mandell JW, Czernik AJ, De Camilli P, Greengard P, Townes-Anderson E (1992) Differential expression of synapsins I and II among rat retinal synapses. J Neurosci 12:1736-1749.

Margolis FL (1972) A brain protein unique to the olfactory bulb: isolation and immunological studies. Proc Natl Acad Sci USA 69: 1221-1224.

Monti-Graziadei GA, Margolis FL, Harding JW, Graziadei PPC (1977) Immunocytochemistry of the olfactory marker protein. J Histochem Cytochem 25:1311-1316.

Moulton DG (1974) Cell renewal in the olfactory epithelium of the mouse. In: Conference on odors: evaluation, utilization and control (Cain WS, ed), pp 52-61. New York: New York Academy of Science.
Moulton DG, Celebi G, Fink RP (1970) Olfaction in mammals-two aspects: proliferation of cells in the olfactory epithelium and sensitivity to odours. In: Taste and smell in vertebrates (Wolstenholme GEW, Knight J, eds), pp 227-246. London: Churchill.

Nadi NS, Head R, Grillo M, Hempstead J, Grannot-Reisfeld N, Margolis FL (1981) Chemical deafferentation of the olfactory bulb: plasticity of the levels of tyrosine hydroxylase, dopamine and norepinephrine. Brain Res 213:365-377.

Scott JW, Harrison TA (1987) The olfactory bulb: anatomy and physiology. In: Neurobiology of taste and smell (Finger TE, Silver WL, eds), pp 151-178. New York: Wiley.

Südhof TC, Czernik AJ, Kao H, Takei K, Johnston PA, Horiuchi A Kanazir SD, Wagner MA, Perin MS, De Camilli P, Greengard P (1989) Synapsins: mosaics of shared and individual domains in a family of synaptic vesicle phosphoproteins. Science 245:1474-1480.

Walaas SI, Browning MD, Greengard P (1988) Synapsin Ia, synapsin $\mathrm{Ib}$, protein IIIa, and protein IIIb, four related synaptic vesicle-associated phosphoproteins, share regional and cellular localization in rat brain. J Neurochem 51:1214-1220. 